Textures and Microstructures, Vol. 33, pp. 45-60 Reprints available directly from the publisher Photocopying permitted by license only
(C) 1999 OPA (Overseas Publishers Association) N.V. Published by license under the Gordon and Breach Science Publishers imprint. Printed in Malaysia.

\title{
LATTICE PREFERRED ORIENTATION AS AN INDICATOR OF A COMPLEX DEFORMATION HISTORY OF ROCKS
}

\author{
K. ULLEMEYER ${ }^{\mathrm{a}, \mathrm{b}, *}$ and K. WEBER ${ }^{\mathrm{a}}$ \\ a Institut für Geologie und Dynamik der Lithosphäre, Universität Göttingen, \\ D-37077 Göttingen, Germany; b Joint Institute of Nuclear Research, Frank \\ Laboratory for Neutron Physics, 141980 Dubna, Moscow Region, Russia
}

The deconvolution of the deformation history of rocks is one of the main goals of texture analysis in geology. The frequent observation that the macroscopic structures are obliquely oriented with respect to the margins of the deformation zone gave rise to the hypotheses that the deformation path might be complex, and that the lattice preferred orientation of the rock-forming minerals should reflect such complicated deformation conditions as well. Hence, texture determinations of polyphase rock samples were carried out and the relationship of the mineral textures to the commonly used sample reference frame foliationlineation, which is assumed to represent the principal axes of the bulk finite strain tensor, was investigated. It was confirmed that particular mineral textures are typical for different stages of the deformation path. Especially the quartz textures exhibit an uncommon but consistent deviation from the sample reference frame, which is consistent with respect to the geographical coordinates, too. Such a characteristic may be used to evaluate the direction of a large-scale horizontal shear component, which is known as the transpressive shear vector in the geological literature.

Keywords: Quantitative texture analysis; Textures of polyphase rocks; Transpressive deformation

\section{INTRODUCTION}

In geology, texture investigations are applied because of three reasons: (1) to deconvolute the deformation history of rocks, e.g. to determine the direction of tectonic transport from the symmetry of the mineral

\footnotetext{
* Corresponding author.
} 
textures, (2) to model anisotropic physical rock properties, e.g. the propagation velocity of elastic waves in order to obtain information about the seismic behaviour of the earth's interior, and (3) to discover the mechanisms of texture formation. This paper is related to the first topic and presents examples as to how the quantitative texture analysis of polyphase rocks may be used to improve the knowledge about rock deformation in a region, that is characterized by a complicated deformation history.

Our investigations were initiated by the observation that tectonic uplift and nappe thrusting as well are often accompanied by considerable horizontal (strike-slip) movements of crustal blocks. The resulting type of deformation was termed 'transpressive' (Harland, 1971). In contrast to simple 'orthogonal' movements with an unchanging and dip-parallel moving direction, transpressive deformation is characterized by a displacement vector, which is obliquely inclined to the direction of dip (see Fig. 1). Moreover, different paths may lead to the same final displacement, they depend upon changes in the relative contribution of the two components of motion in the course of time. Crustal movements generally manifest in deformed rocks in the vicinity of the movement zone.

\section{orthogonal}

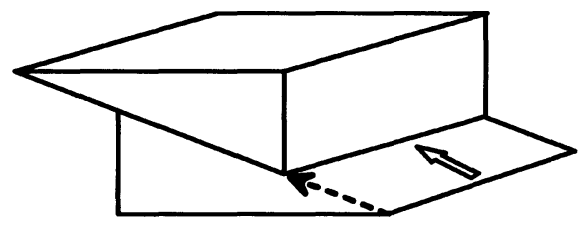

\section{transpressive}

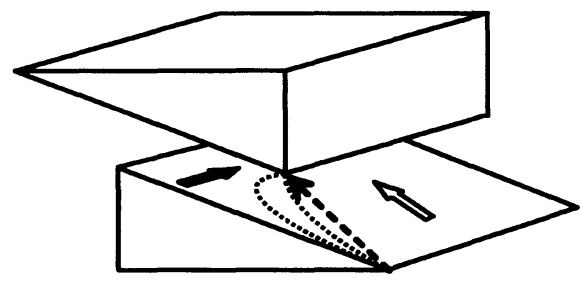

FIGURE 1 Simplified sketch to visualize transpressive displacement. In addition to dip-parallel 'orthogonal' motion (open arrows), a horizontal component (filled arrow) causes an obliquely inclined displacement vector (dashed arrows). Different paths (dashed lines) may lead to the same final displacement during transpressive deformation. 
It may be easily inferred that the orientation and the shape of the recorded finite and incremental strain tensors of such deformed rocks depend upon the strain path, which might be complicated. For linear displacement paths, the modelling of transpressive deformation theoretically predicts the shape and the orientation of the finite strain tensor, of the incremental strain tensor, and the orientation of the macroscopic fabric elements (e.g. lineations, fold axes, faults) with respect to the boundaries of the deformation zone (Sanderson and Marchini, 1984). Since the deformation usually manifests in the development of lattice preferred orientation of the rock-forming minerals (Law, 1990), too, the question arises as to how textures develop in a transpressive deformation regime.

Until recently, texture analyses of rocks were mainly applied to monophase samples despite the fact that rocks usually are polyphase composites (refer to reviews by Mainprice and Nicolas, 1989; Drury and Urai, 1990; Wenk and Christie, 1991; Schmid, 1994). In order to obtain the more complete fabric information the texture investigations were carried out on a number of rock-forming minerals, namely, quartz, biotite, plagioclase and sillimanite (if present). Due to dissimilar rheological behaviour and reorientation mechanisms the relationship of the mineral textures to the deformation path is different. The predominant reorientation mechanism of quartz (trigonal) and plagioclase (triclinic) is dislocation slip, whereas the texture of monoclinic biotite is controlled by its tabular grain shape. The normal to the biotite tablets nearly parallels the $(00 l)$ lattice direction, the $(00 l)$ pole-figure therefore represents an integral image of all planar fabric elements in the investigated sample volume. Orthorhombic sillimanite with its needle-like appearance (the $(00 l)$ direction parallels its long axis) reorients due to its anisotropic grain shape, too, but represents a linear fabric. Its preferred orientation should correlate with the direction of maximal finite elongation. Considering the textures of all these mineral phases, a more complete information on the deformation history can be achieved.

\section{GEOLOGICAL FRAMEWORK AND SAMPLE DESCRIPTION}

The samples were collected in the Moldanubian Zone of the Bohemian Massif in Lower Austria. The internal structure of the Moldanubian Zone is characterized by nappe tectonics (Kober, 1938), where the 
margins of the main structural units correspond to major thrust planes (see Fig. 2). Hence, the tectonic units represent single nappes or nappe complexes as well, which additionally may be cut by secondary thrust planes. Intense field work led to detailed knowledge of the macroscopical structures and of the deformation history (Fuchs and Matura,
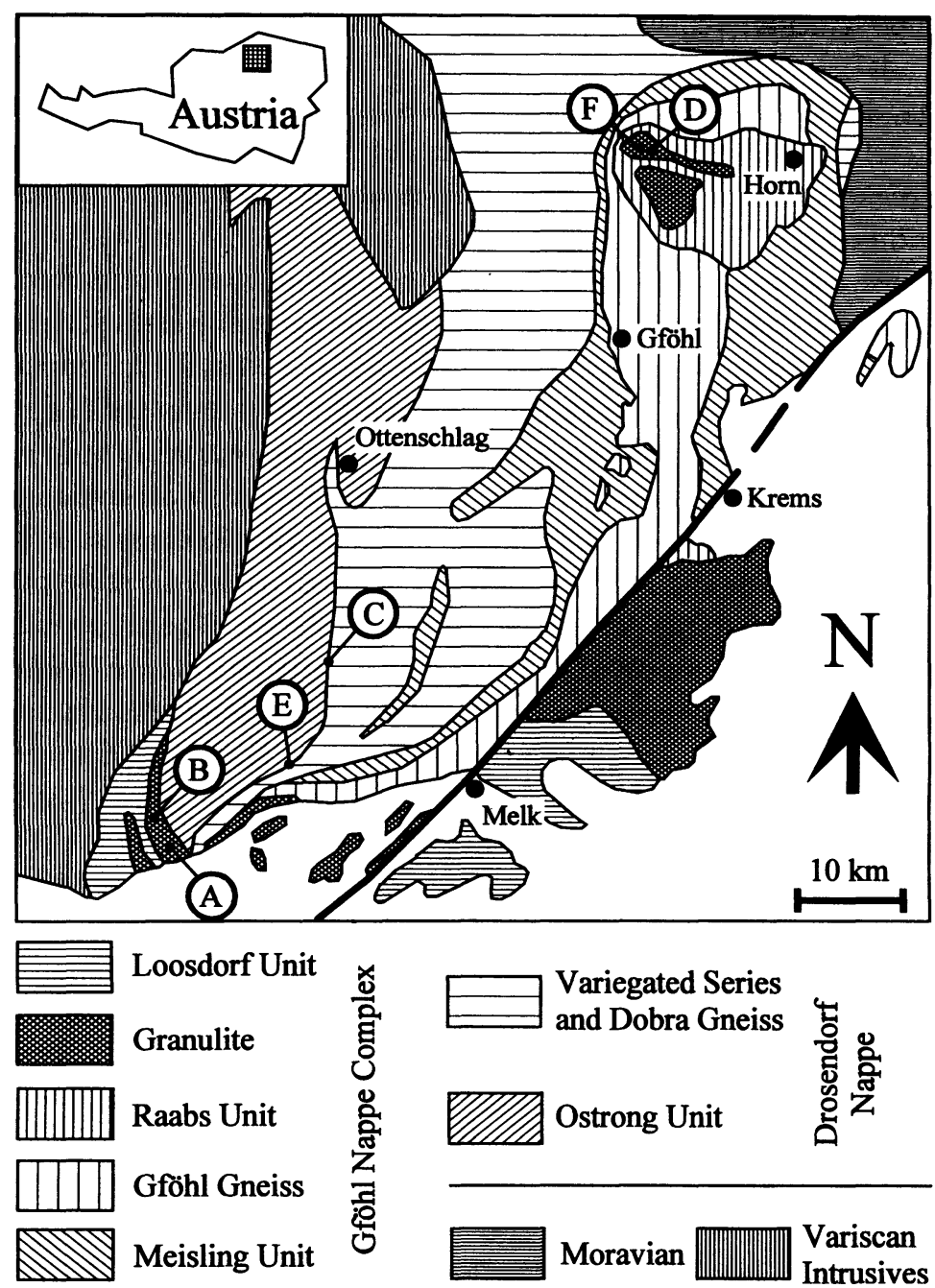

FIGURE 2 Generalized geological map of the Moldanubian Zone in Lower Austria. The sample locations $(\mathbf{A}-\mathbf{F})$ are indicated by capital letters. 
1980; Matura, 1984; Thiele, 1984; Fuchs, 1986). From the total available data, transpressive deformation was inferred (Fritz and Neubauer, 1993); the region is therefore well-suited to analyse the effect of transpressive deformation on the development of the mineral textures. For our specific investigations we focused on highly strained granulites (Scharbert, 1963; 1964; Fuchs and Scharbert, 1979). From the large accumulated strain was assumed, that the main rock-forming minerals, even feldspars, developed lattice preferred orientation. The samples originate from different granulite types: from broad granulite layers (their width is several hundred meters, the lateral extension is tens of kilometers or less; sample locations A and B in Fig. 2), from small granulite lenses, which are incorporated in the thrust planes (the dimensions of the lenses are some meters; sample locations $\mathrm{C}$ and $\mathrm{E}$ ), and from the St. Leonhard granulite complex west of the city of Horn, which represents one of the large granulite complexes of the Lower Austrian Moldanubian (sample locations D and F).

A common feature of all investigated samples is a very strong mylonitic layering, frequently, a pronounced stretching lineation is observed. Such characteristics confirm a large amount of bulk strain and are one of several arguments to interpret the Lower Austrian granulites as hightemperature mylonites. Due to the high strain, shear sense indicators (e.g. porphyroclasts with asymmetric mantles of recrystallized material) are scarce. If shear sense indicators are present, no unique shear sense may be inferred. The granulites are mainly composed of quartz, plagioclase, $\mathrm{K}$-feldspar and biotite with varying volume fractions. In addition, garnet, kyanite and sillimanite may be present. Samples containing considerable amounts of $\mathrm{K}$-feldspar were avoided to reduce the number of peak overlappings and to reduce experimental and methodical errors (refer to Ullemeyer, 1996 for details). The average volume fractions of the interesting phases are: quartz and plagioclase $40 \pm 5 \%$, biotite $10 \pm 3 \%$, sillimanite $<1 \%$. Coarse grained samples were avoided as well to ensure a sufficiently large number of grains. The average grain size of all samples covers the range from 100 to $300 \mu \mathrm{m}$.

\section{METHODS}

Neutron texture measurements were performed to evaluate the quartz, biotite and plagioclase textures. Neutrons allow the investigation of 


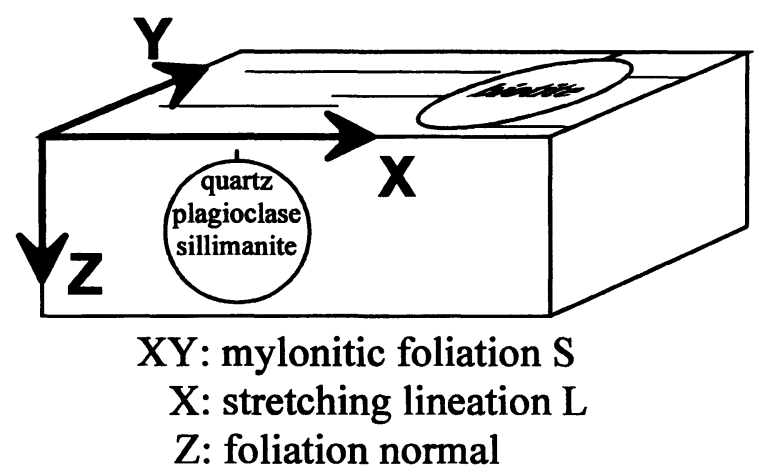

FIGURE 3 The commonly used sample reference system in geology, which is assumed to represent the axes of the finite strain tensor with its principal axes $X, Y, Z$. Pole-figures are generally given in the $\mathbf{X Z}$ section, except the biotite $(00 l)$ pole-figures, which are projected onto the foliation plane.

large sample volumes to obtain sufficient counting statistics even for minerals, which are represented only by small volume fractions. The measurements were carried out at the neutron diffractometer NSHR at the pulsed reactor IBR-2 in Dubna, Russia (Walther et al., 1995). Timeof-flight spectra were recorded for a regular $7.2^{\circ}$ grid; subsequently, all desired pole-figures were extracted by integration over the intensities in a distinct $d$-range of the spectra ( $d$ : lattice spacing). Each pole-figure may contain several Bragg reflection, they are deconvoluted during Quantitative Texture Analysis (QTA). QTA of the neutron derived pole density data was done by means of the component method (Helming and Eschner, 1990). This method deals with any crystal symmetry and allows the simultaneous calculation of the textures of all present phases. It is therefore advantageous for the texture investigation of polyphase rocks. For details on the mathematical background refer to original work and recent applications to geological materials (Bunge et al., 1994). The sillimanite $(00 l)$ axes distributions were measured in a thin section perpendicular to the stretching lineation L (see Fig. 3) on a Leitz U-stage; subsequently, pole density distributions were calculated from the single grain directional data.

\section{DESCRIPTION OF THE RESULTS}

Usually, the pole-figures are displayed in the $\mathbf{X Z}$ section of the finite strain tensor (with its principal axes $\mathbf{X}, \mathbf{Y}$ and $\mathbf{Z} ;|\mathbf{X}|>|\mathbf{Y}|>|\mathbf{Z}|$ ), which is 
assumed to be given by the foliation $S$ and the stretching lineation $L$ (see Fig. 3). Since strike-slip movements in the lithosphere are controlled by the force of gravity, the orientation of the finite strain tensor should be related not only to the commonly used reference frame, but to the earth coordinates, too. As a reference to the scope of the paper, they are related to the geographical coordinates in the following way: the normal onto the foliation plane appears at the top of the pole plot, the direction of view is to a northern direction (lower hemisphere projection). The biotite $(00 l)$ pole-figures, however, are projected onto the foliation plane, the stretching lineation strikes horizontal as well. This section is more advantageous to judge the pole-figures, since biotite $(00 l)$ intensity distributions generally possess a single intensity maximum parallel to the foliation normal.

\section{Quartz}

The symmetry of the quartz textures is either axial symmetric or orthorhombic. The most perfect axial symmetry is observed for sample 96 (Fig. 4). Predominant coaxial flattening strain is generally deduced from this type of texture (Schmid and Casey, 1986). The $\langle 11 \overline{2} 0\rangle$ polefigures of the samples 15.9.88/7 (Fig. 5) and W97 (Fig. 6) display approximately orthorhombic intensity distributions with distinctively elongated maxima along small circles, which are centred close to the foliation pole. This trend is not so clear in the 0001 pole-figures. From this kind of intensity distribution it is generally concluded that the deformation was dominated by flattening. The samples $30.8 .90 / 3$ and $30.8 .90 / 1$ show orthorhombic intensity distributions with circular maxima in the $\langle 11 \overline{2} 0\rangle$ pole-figure (Figs. 7 and 8 ). This indicates plane strain deformation conditions. The symmetry of the texture of sample 13.9.88/ 3 is orthorhombic, too, but the $\langle 11 \overline{2} 0\rangle$ pole-figure shows an uncommon intensity distribution with a distinct maximum in the foliation plane. Slight differences in the intensity of the maxima in all $\langle 11 \overline{2} 0\rangle$ pole-figures indicate an additional simple shear component. However, the inferred sense of rotation is not consistent with the other samples.

The most remarkable feature of most of the quartz textures is the deviation from the external reference frame (foliation-lineation), which corresponds to a lowering of the external symmetry. In the quartz $\langle 11 \overline{2} 0\rangle$ pole-figures, this deviation is characterized by a great circle, which connects the kinematically significant maxima. According to this, 


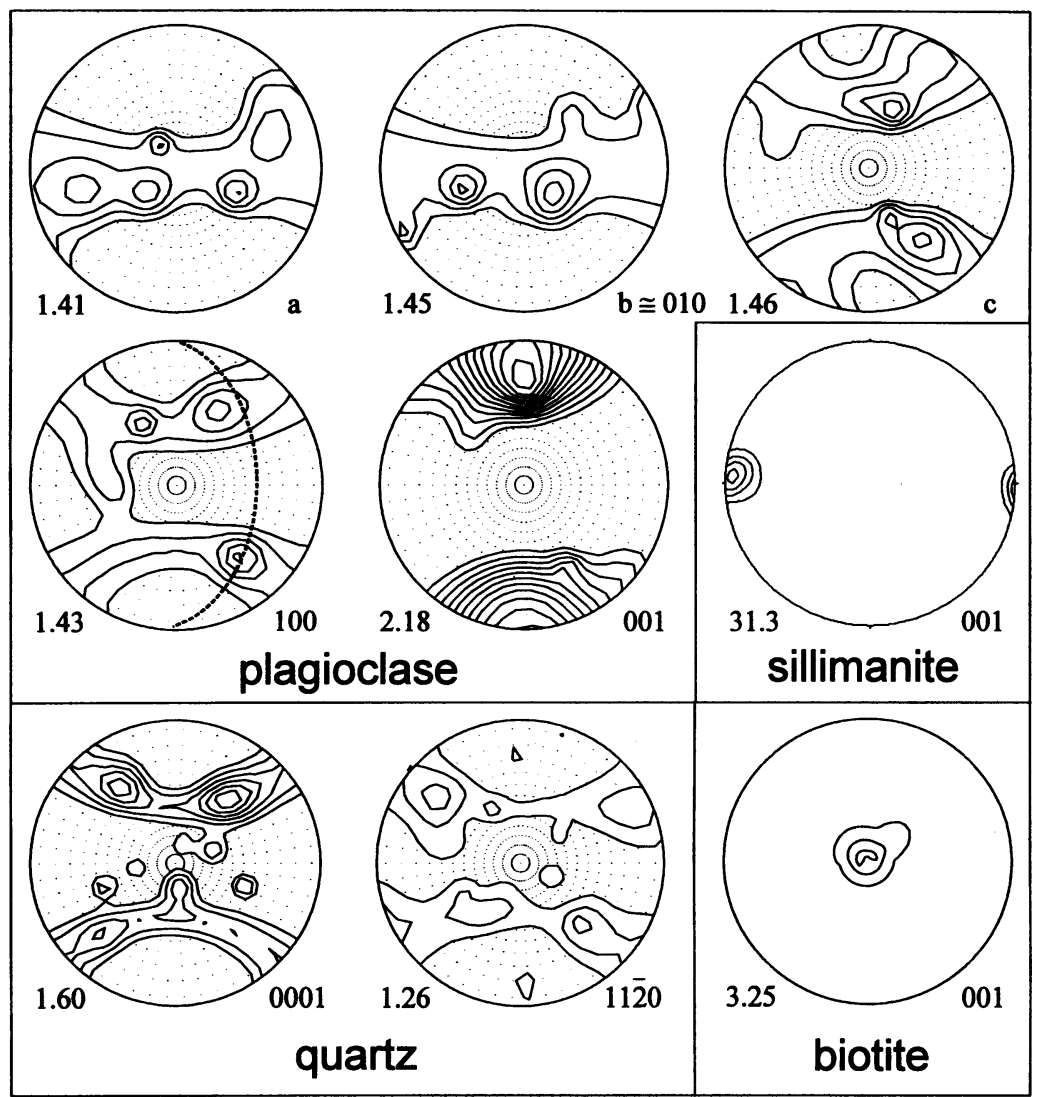

FIGURE 4 Recalculated pole-figures of sample 96 (sample location C). Contouring begins at one time random, the maximum intensity is given at the bottom left of each pole-figure.

the (0001) axes skeleton does not intersect the centre of the pole-figure, but is more or less shifted (as indicated by a rhomb at the pole position of the great circle in the $\langle 11 \overline{2} 0\rangle$ pole-figures). This deviation from the reference frame may be described as an external rotation about a virtual axis; its spatial orientation may be approximately determined in the $\langle 11 \overline{2} 0\rangle$ pole-figure. The rotation is only descriptive and does not imply any mechanism. The degree of rotation is about $25^{\circ}$ or less, the orientation of the virtual rotation axis is located close to the foliation pole. In the case of sample 13.9.88/3 (Fig. 9), an external rotation of the texture 


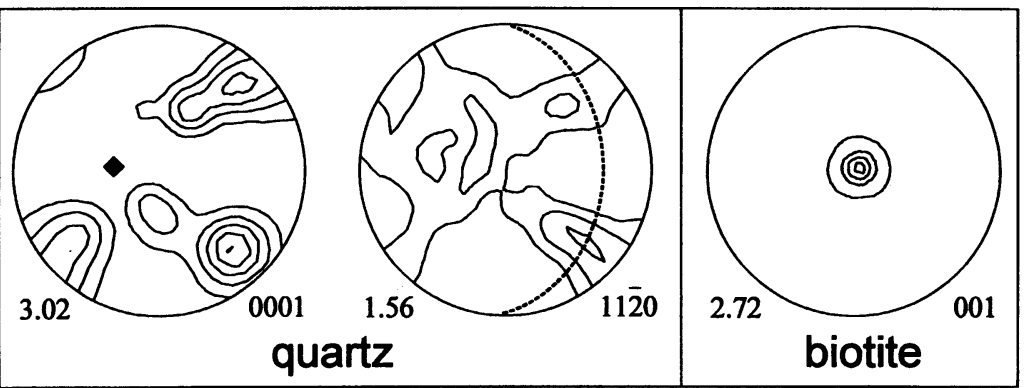

FIGURE 5 Recalculated pole-figures of sample 15.9.88/7 (sample location B). No preferred orientation of plagioclase could be detected. For further explanations refer to Fig. 4.

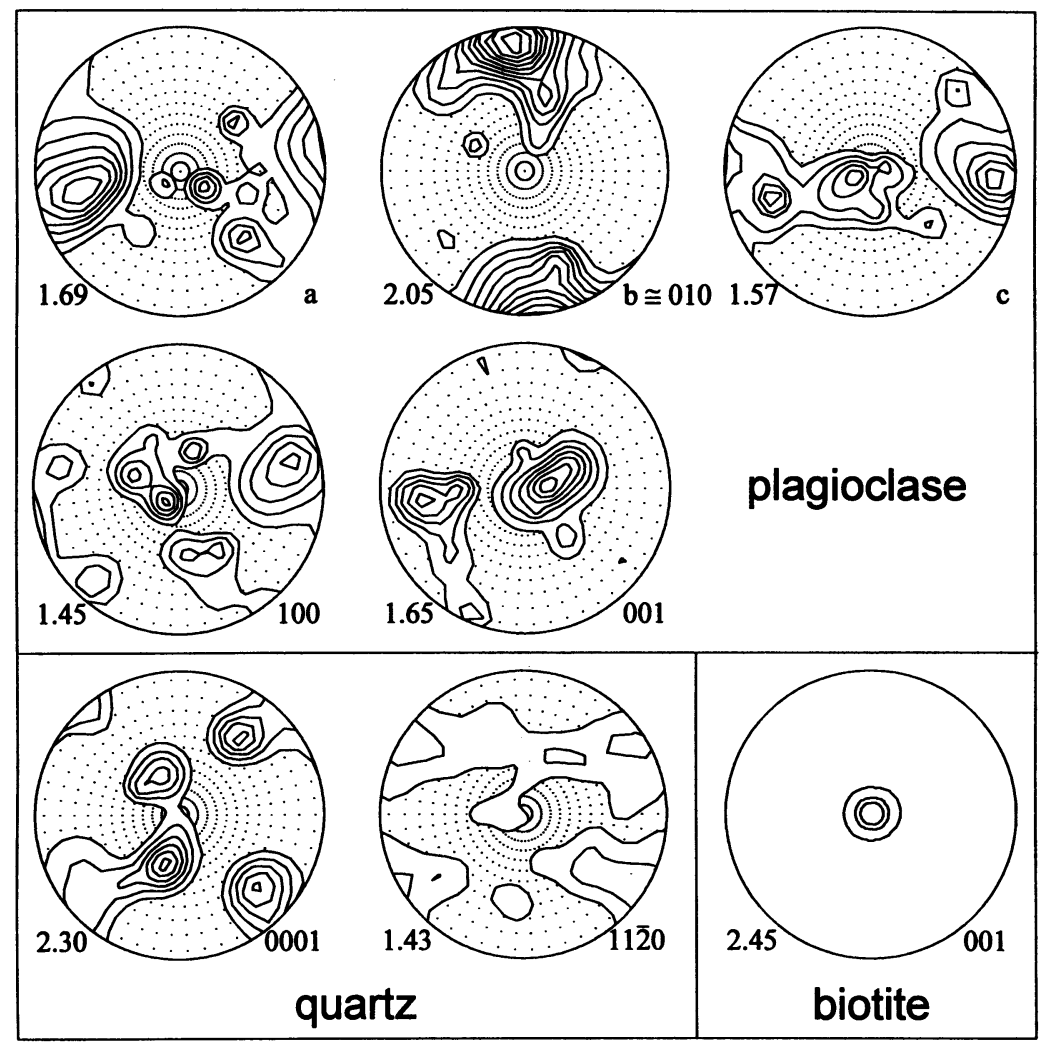

FIGURE 6 Recalculated pole-figures of sample W97 (sample location E). For further explanations refer to Fig. 4. 


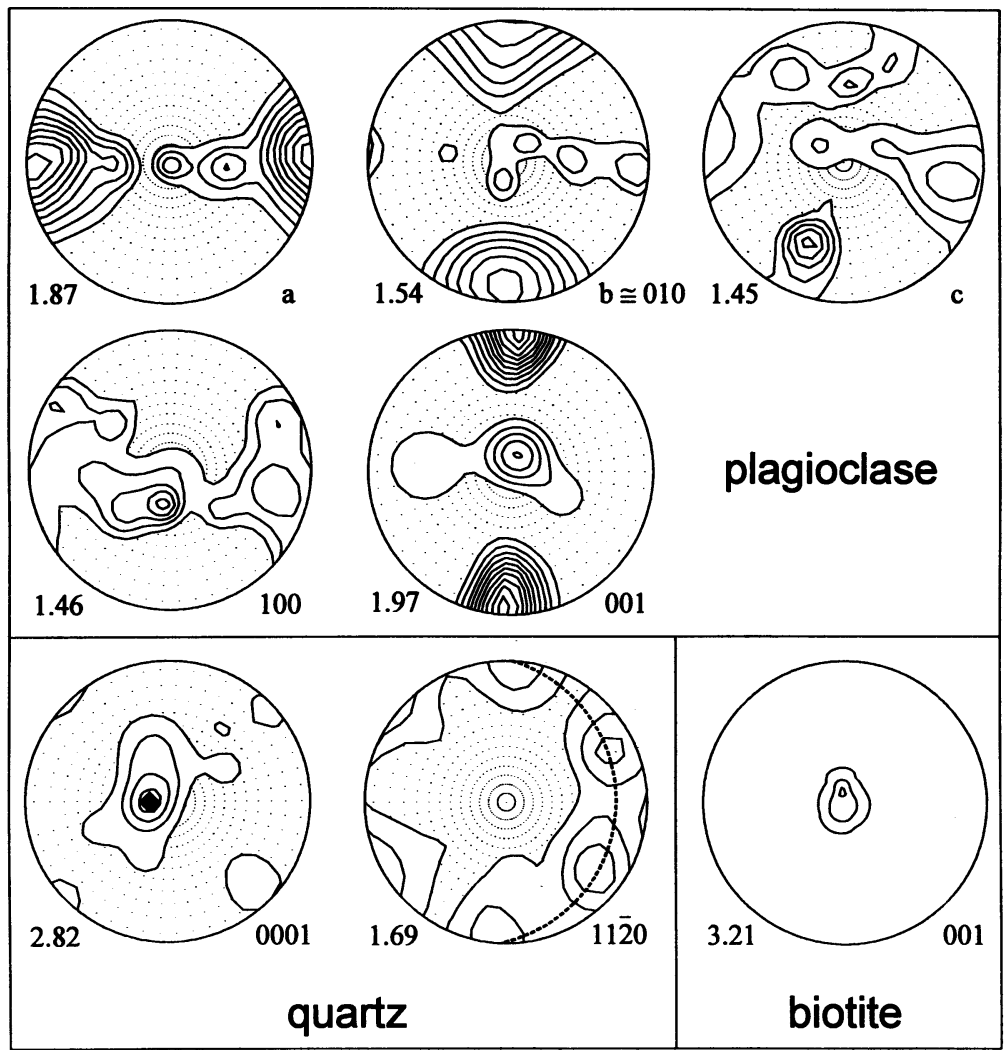

FIGURE 7 Recalculated pole-figures of sample 30.8.90/3 (sample location D). For further explanations refer to Fig. 4.

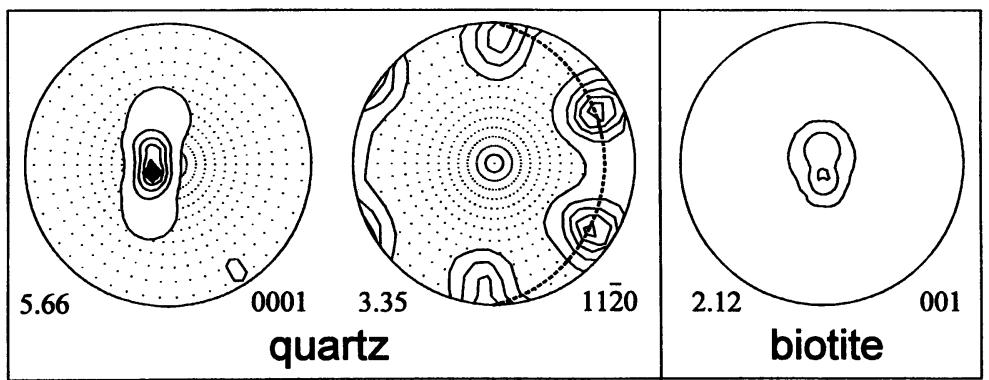

FIGURE 8 Recalculated pole-figures of sample 30.8.90/1 (sample location F). No preferred orientation of plagioclase could be detected. For further explanations refer to Fig. 4. 


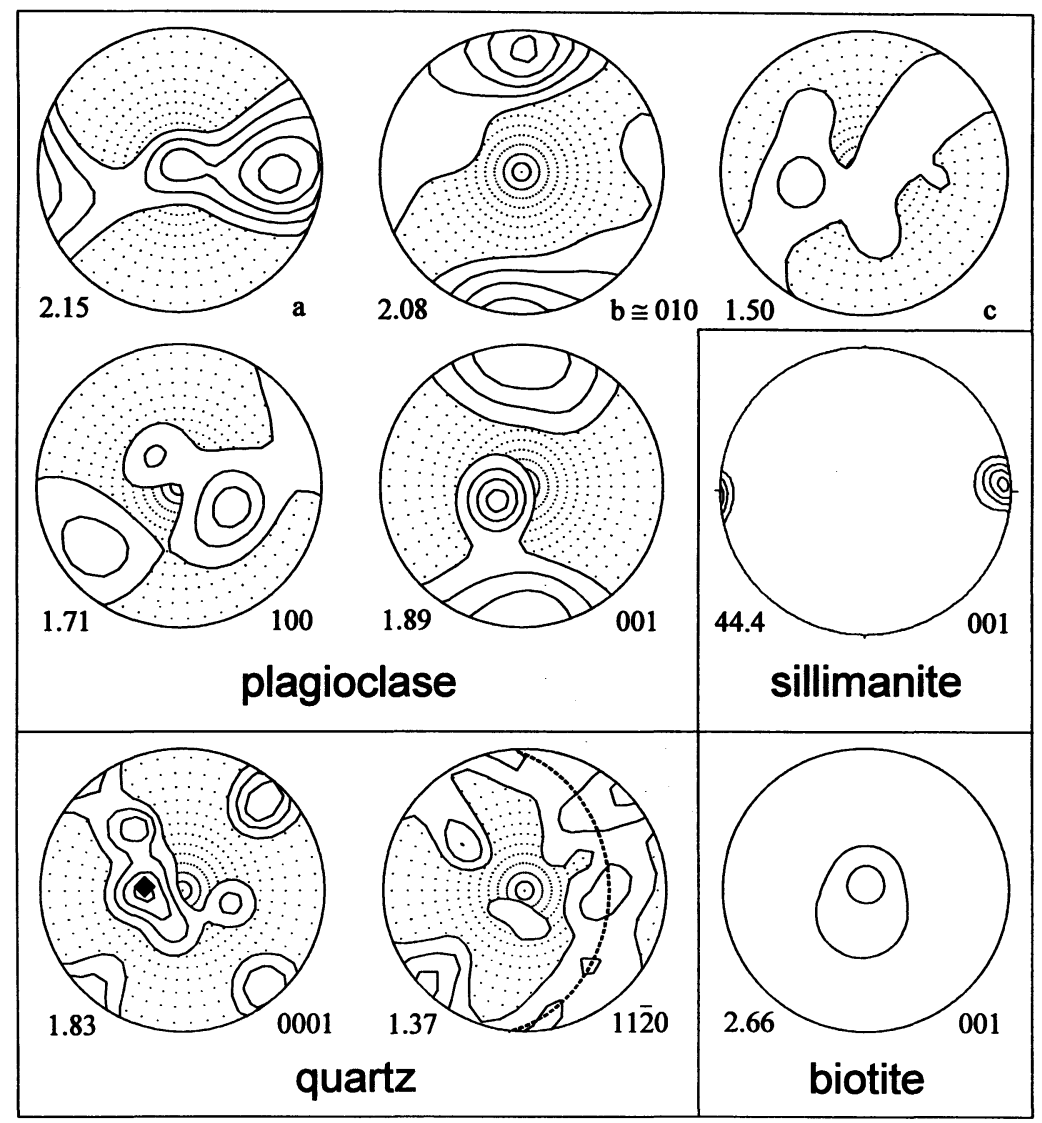

FIGURE 9 Recalculated pole-figures of sample 13.9.88/3 (sample location A). For further explanations refer to Fig. 4.

is not obvious in the $\langle 11 \overline{2} 0\rangle$ pole-figure, but it can be deduced from the (0001) pole-figure. The intensity distribution may be described as a crossed-girdle pattern, which does not intersect the centre of the polefigure. In accordance, the basal submaxima are not located at the border of the pole-plot.

As a further feature it should be noted that the sense of rotation is consistent for all textures. Since the pole-figures are consistently oriented with respect to the geographical reference frame, it is also consistent with respect to the geographical coordinates (anti-clockwise in map view). 


\section{Biotite}

The intensity patterns of biotite (00l) show a unimodal maximum parallel to the foliation normal. The maximum is either axial symmetric (samples 96, 15.9.88/7, W97) or elongated (samples 30.8.90/1, 30.8.90/3, 13.9.88/3), the elongation is perpendicular to the lineation and less pronounced. No significant deviation of the intensity distribution from the axes of the sample coordinate system as in the case of quartz is observed.

\section{Plagioclase}

The plagioclase textures are much more complicated compared to the textures of the other minerals. In agreement with the quartz texture its symmetry is rotational in the case of sample 96 (Fig. 4); nevertheless, distinct maxima on the small circle intensity distributions developed. The predominant glide system seems to be (001)[100] (Kruhl, 1987). It is a remarkable feature of that texture that the kinematically significant [100] axes show consistent deviation from the reference frame and consequently from the geographical coordinates as the quartz texture does. The textures of the other samples are much more difficult to interpret, since they do not reflect any of the predominant glide systems of plagioclase ((010)[001] and (001)[100], refer to Kruhl, 1987). Sample 30.8.90/3 (Fig. 7) shows very clear intensity distributions with orthorhombic symmetry; in contrast, most other samples display weaker or even no preferred orientation. On condition that the crystallographic $a$ axis represents the predominant glide direction, the deviation of the maximum in the corresponding pole-figure of sample 13.9.88/3 (see Fig. 9) might be interpreted as a significant feature of that texture. Nevertheless, due to the uncertainty concerning the active reorientation mechanisms, such an interpretation may be erratic.

\section{Sillimanite}

Two samples contain prismatic sillimanite; both $(00 l)$ pole-figures display a sharp maximum close to the stretching lineation (see Figs. 4 and 9). This observation is especially of interest in the case of sample 96 , since the textures of all other minerals display axial symmetry with the symmetry axis parallel to the foliation normal, and no lineation is visible on the foliation plane. It gives rise to the assumption that the strain was 
anisotropic in the foliation plane, too, although the textures of all the other minerals do not support this conclusion.

\section{DISCUSSION}

Uncommon quartz textures were described from several regions of the world, and various reasons were discussed to explain their strange relationship to the macroscopic structure elements. Oblique quartz textures in a fold structure could be related to a minor lineation on the folded rock foliation which does not parallel the fold axis (Sesia Zone, Western Alps; Stünitz, 1991). An alternative projection plane containing the secondary lineation could be defined, with the consequence that 'ordinary' intensity distributions were obtained in the alternative section. Oblique post-folding simple shear deformation was assumed to control the texture development; the orientation of the accompanying finite strain tensor did not correspond to the orientation of the foldrelated tensor. Similar relations were observed at other locations of the Western Alps as well (Klaper, 1988). In both cases, the presence of an alternative reference frame offers the basis for an ingenious explanation of the obliqueness of the textures.

The relation of oblique quartz $c$-axis patterns to the geographical coordinates was recently described by MacCready (1996). Based on a great number of $c$-axis measurements he discovered geographical consistent deviations of most of the $c$-axis patterns from the usual reference frame. Such consistency is an indicator for the influence of large-scale processes on the texture modifying processes and contradicts the widespread interpretation of uncommon intensity distributions as local phenomena.

Moreover, exceptional internal mechanisms may be an explanation for uncommon textures. Mancktelow (1987) found atypical quartz textures, too, but correlated them with microfabrics he observed only in the atypical samples. He explained such characteristic microfabrictexture relations as the effect of unusual internal texture-forming processes. Since no indication to a differing finite strain tensor was found, an interpretation of that kind is reasonable.

Based on the well-known deformation history of the Lower Austrian Moldanubian Zone that clearly confirms transpressive deformation as the large-scale deformation regime, the interpretation of the observed 
uncommon quartz textures as the result of an oblique latest strain increment seems to be well-founded. The conclusions are at least based on contrasts in the rheological behaviour of the considered minerals. The recrystallization temperatures of quartz and plagioclase are quite different $\left(300^{\circ} \mathrm{C}\right.$ and $>450^{\circ} \mathrm{C}$, respectively); hence, the response of quartz on external stress at decreasing temperature is still ductile, whereas plagioclase already shows brittle behaviour. It can be easily inferred that the quartz texture still suffers changes and therefore is competent to record the latest strain increment, whereas the plagioclase texture remains unchanged and consequently indicates an older strain increment. Differences in the orientation of the 'mineral tensors' are visible only in the case of oblique (in this connection: transpressive) deformation. During orthogonal thrusting, the orientation of the intermediate (Y) axes of all incremental strain tensors and consequently of the bulk strain tensor is the same. Orientation changes are valid only for the $\mathbf{X}$ and $\mathbf{Z}$ directions, i.e. the intermediate axis corresponds to the rotation axis which brings the $\mathbf{X}$ and $\mathbf{Z}$ directions of the bulk and incremental tensor to an agreement. Since large amounts of strain at least result in a 'locked' orientation of the bulk finite strain tensor (i.e. ongoing deformation no longer causes visible changes), the strain tensors are indiscernible. In a transpressive deformation regime the intermediate direction of the incremental strain tensor changes its orientation as well due to the horizontal shear component. The resulting bulk deformation tensor therefore deviates from the strain tensor related to the final strain increment, but in a different way, since the rotation axis does not parallel the $\mathbf{Y}$ axis. The orientation difference becomes visible now in the form of the observed deviation of the quartz textures from the sample reference frame. The virtual rotation axis may have any orientation depending upon the spatial (geographical) orientation of foliation and lineation; it does not necessarily parallel the foliation normal. It must be assumed that in case of large angles between foliation normal and rotation axis, uninterpretable intensity distributions may also result. Moreover, the amount of bulk strain is generally much larger as the amount of the final strain increment, with the consequence that the orientation difference between both tensors is generally small.

Biotite $(00 l)$ preferred orientations, which represent an integral image of all planar fabric elements in the investigated sample volume, and sillimanite (001) preferred orientations, which reproduce the direction 
of maximal finite extension, correspond to the orientations of foliation and stretching lineation; they represent the orientation of the bulk finite strain tensor. Since foliation and lineation are quite insensitive to strain changes, they correlate with a relatively older strain increment in the same way as the plagioclase texture does.

\section{CONCLUSIONS}

Uncommon quartz textures are not necessarily the consequence of a very complicated deformation history or of unusual texture-forming processes. In case of transpressive deformation they may represent suitable indicators to evaluate the direction of the transpressive shear vector, at last based on the extremely viscous behaviour of quartz even at low temperature. Plagioclase textures are difficult to interpret in that connection, since the deformation mechanisms are not as well-known compared to quartz. Biotite $(00 l)$ preferred orientations represent a suitable indicator for the main rock foliation. In case of ellipsoidal intensity distributions they additionally mark the bulk stretching direction, which generally parallels the axis of the elongated intensity maximum. Even accessory minerals may carry information about the deformation history of rock: sillimanite $(00 l)$ preferred orientations could be used to determine the direction of maximal finite extension in the absence of a stretching lineation.

Moreover, it should be pointed out clearly that especially the quartz textures are not only local phenomena but represent an important fabric element of deformed rocks, which allows conclusions on the deformation history of a whole region.

\section{Acknowledgements}

The authors are grateful to B. Leiss and A. Vollbrecht (Göttingen) for critical comments. Support of the German Bundesminister für Bildung, Wissenschaft, Forschung und Technologie through grant 03DU4GOE-8 is also gratefully acknowledged.

\section{References}

Bunge, H.-J., Siegesmund, S., Skrotzki, W. and Weber, K. (1994). Textures of Geological Materials. DGM Special Publication, Oberursel. 
Drury, M.R. and Urai, J.L. (1990). Deformation-related recrystallization processes. Tectonophysics 172, 235-253.

Fritz, H. and Neubauer, F. (1993). Kinematics of crustal stacking and dispersion in the south-eastern Bohemian Massif. Geol. Rundsch. 82, 556-565.

Fuchs, G. (1986). Zur Diskussion um den Deckenbau der Böhmischen Masse. Jb. Geol. B. - A. 129, 41-49.

Fuchs, G. and Matura, A. (1980). Die Böhmische Masse in Österreich. In: Der geologische Aufbau Österreichs (Ed. Oberhauser, R.). Springer, Berlin.

Fuchs, G. and Scharbert, H.G. (1979). Kleinere Granulitvorkommen im niederösterreichischen Moldanubikum und ihre Bedeutung für die Granulitgenese. Verh. Geol. B.-A. 2, 29-49.

Harland, W.B. (1971). Tectonic transpression in Caledonian Spitsbergen. Geol. Mag. 108, $27-42$.

Helming, K. and Eschner, T. (1990). A new approach to texture analysis of multiphase materials using a texture component model. Cryst. Res. Technol. 25, K203-K208.

Klaper, E.M. (1988). Quartz c-axis fabric development and large-scale post-nappe folding (Wandfluhhorn Fold, Penninic nappes). J. Struct. Geol. 10, 795-802.

Kober, L. (1938). Der geologische Aufbau Österreichs, Wien.

Kruhl, J.H. (1987). Zur Deformation und Gitterregelung des Plagioklases. Jb. Geol. B.-A. 130, 205-243.

Law, R.D. (1990). Crystallographic fabrics: a selective review of their applications to research in structural geology. In: Deformation Mechanisms, Rheology and Tectonics (Eds. Knipe, R.J. and Rutter, E.H.). Geol. Soc. Spec. Publ. Vol. 54, pp. 335-352.

MacCready, T. (1996). Misalignment of quartz $c$-axis fabrics and lineations due to oblique final strain increments in the Ruby Mountains core complex, Nevada. J. Struct. Geol. 18, 765-776.

Mainprice, D. and Nicolas, A. (1989). Development of shape and lattice preferred orientations: application to the seismic anisotropy of the lower crust. J. Struct. Geol. 11, 175-189.

Mancktelow, N.S. (1987). Atypical textures in quartz veins from the Simplon Fault Zone. J. Struct. Geol. 9, 995-1005.

Matura, A. (1984). Das Kristallin am Südostrand der Böhmischen Masse zwischen Ybbs/ Donau und St. Pölten. Jb. Geol. B.-A. 127, 13-27.

Sanderson, D.J. and Marchini, W.R.D. (1984). Transpression. J. Struct. Geol. 6, 449-458.

Scharbert, H.G. (1963). Die Granulite des südlichen niederösterreichischen Moldanubikums I. N. Jb. Min. Abh. 100, 59-86.

Scharbert, H.G. (1964). Die Granulite des südlichen niederösterreichischen Moldanubikums II. N. Jb. Min. Abh. 101, 27-66.

Schmid, S.M. (1994). Textures of geological materials: computer model predictions versus empirical interpretations based on rock deformation experiments and field studies. In : Textures of Geological Materials (Eds. Bunge, H.-J., Siegesmund, S., Skrotzki, W. and Weber, K.). DGM Special Publication, pp. 279-203.

Schmid, S.M. and Casey, M. (1986). Complete fabric analysis of some commonly observed quartz c-axis patterns. Geophysical Monograph 36, 263-286.

Stünitz, H. (1991). Folding and shear deformation in quartzites, inferred from crystallographic preferred orientation and shape fabrics. J. Struct. Geol. 13, 71-86.

Thiele, O. (1984). Zum Deckenbau und Achsenplan des Moldanubikums der Südlichen Böhmischen Masse (Österreich). Jb. Geol. B.-A. 126, 513-523.

Ullemeyer, K. (1996). Error estimation of multiphase pole-density measurements by TOF neutron diffraction: Application to a granulite. Z. Geol. Wiss. 24, 671-678.

Walther, K., Heinitz, J., Ullemeyer, K., Betzl, M. and Wenk, H.-R. (1995). Time-of-flight texture analysis of limestone standard: Dubna results. J. Appl. Cryst. 28, 503-507.

Wenk, H.-R. and Christie, J.M. (1991). Comments on the interpretation of deformation textures in rocks. J. Struct. Geol. 13, 1091-1110. 